\title{
MODELO ALTERNATIVO DE FUNCIONAMIENTO DEL SISTEMA TURÍSTICO: DISEÑO Y DESARROLLO METODOLÓGICO DE LA OFERTA TURÍSTICA
}

\author{
Manuel Antonio Abarca Zaquinaula \\ Magister en Profesor-Investigador en Turismo \\ Escuela Superior Politécnica de Chimborazo-Extensión Norte Amazónica, Ecuador \\ manuel.abarca@espoch.edu.ec
}

\section{Resumen}

Se diseñó y desarrolló metodológicamente el funcionamiento ideal del motor de la oferta turística del modelo alternativo de funcionamiento del sistema turístico (con base en los modelos de Roberto Boullon, Neil Leiper y la OMT), cambiando el enfoque actual de los modelos de desarrollo turístico (desde la oferta) a un enfoque sistémico-mecánico basado en el estudio del nicho ecológico de la demanda turística real y potencial (gustos, preferencias, necesidades, exigencias y tendencias), obteniendo un encadenamiento de competitividad entre todos sus elementos directos e indirectos del turismo, generando innovación turística y tecnológica en los productos diseñados, basados en el uso sostenible de los recursos naturales y culturales. También se identificaron cuatro pasos a seguir para desarrollar eficientemente un destino turístico, con el objetivo de cerrar la brecha existente entre el estado actual del nicho ecológico de la demanda turística y la oferta de productos y servicios turísticos existentes en el destino turístico.

Palabras clave: Dinámica del motor, competitividad, producto turístico, planificación del espacio turístico. 


\title{
ALTERNATIVE MODEL OF OPERATION OF THE TOURIST SYSTEM: DESIGN AND METHODOLOGICAL DEVELOPMENT OF THE TOURIST OFFER
}

\author{
Manuel Antonio Abarca Zaquinaula \\ Magister en Profesor-Investigador en Turismo \\ Escuela Superior Politécnica de Chimborazo-Extensión Norte Amazónica, \\ Ecuador \\ manuel.abarca@espoch.edu.ec
}

\begin{abstract}
It was designed and developed methodologically the ideal operation of the engine of the tourist supply of the alternative model of operation of the tourism system (based on the models of Roberto Boullon, Neil Leiper and OMT), changing the current approach of tourism development models from the supply) to a systemic-mechanical approach based on the study of the ecological niche of the actual and potential tourist demand (tastes, preferences, needs, demands and trends), obtaining a chain of competitiveness between all its direct and indirect elements of tourism, generating tourism and technological innovation in the products designed, based on the sustainable use of natural and cultural attractions. Four steps were also identified to efficiently develop a tourist destination, with the aim of closing the gap between the current state of the ecological niche of tourist demand and the offer of tourism products and services in the tourist destination.
\end{abstract}

Key words: motor dynamics, competitiveness, tourism product, tourism space planning. 


\section{INTRODUCCIÓN}

En 2015 la llegada de turistas a nivel mundial fue de 1.186 millones, que a su vez generaron 1.260.000 millones de dólares de ingresos en los destinos visitados, además en servicio de exportaciones de transporte internacional de pasajeros prestados o no residentes fue de 211.000 millones de dólares. El turismo internacional representa el 7\% de las exportaciones a nivel mundial de bienes y servicios, y como categoría mundial de exportación, ocupa el tercer puesto, tan solo por detrás de combustibles y de productos químicos, y por delante de alimentación y de la industria de automoción (OMT, 2016).

El turismo se encuentra relacionado directamente con la estructura cambiante de la sociedad, segúnlas previsiones, lapoblaciónmundial, llegaránalos 8300 millonesen2030, laesperanza de vida se incrementará en la mayor parte del mundo, los hogares y las familias son ya más diversas y la migración está cambiando el rostro de las sociedades. Todos estos cambios incidirán en el tipo de turista, sus lugares de origen y de destino, los tipos de alojamiento que buscarán y las actividades que desarrollaran durante sus viajes (UNWTO, 2016).

Estas actividades actualmente se realizan en todos los destinos turísticos del mundo, generando millones de divisas turísticas, estas a su vez, son redistribuidas a miles de servidores, empresarios y/o microempresarios turísticos, reactivando las economías de los pueblos. Precisamente la preocupación del autor es que en muchos de estos destinos no funciona a plenitud la industria turística, afectando a las personas más vulnerables de la sociedad económicamente hablando, ya que, al iniciar un emprendimiento en la zona de oferta de destino turístico, experimentan la no presencia de las corrientes turísticas esperadas y se ven obligados a cerrar sus emprendimientos o a vivir modestamente apoyados de otras actividades económicas. Esta mala experiencia la van replicando en la ciudadaníay formanunimaginariocolectivonegativoacercadelosbeneficiosdeestaindustria.

Analizando la problemática antes mencionada, en el presente ensayo se plantea un modelo alternativo de funcionamiento del motor de la oferta turística, con un enfoque sistémicomecánico, en el que se explica que cualquier destino turístico puede armarlo y gozar de sus beneficios, para mayor detalle se desarrolla a continuación una serie de pasos ordenados a seguir para obtener un desarrollo endógeno de la oferta de un destino turístico, con base en los gustos, preferencias, necesidades, exigencias y tendencias de las corrientes turísticas.

\section{METODOLOGÍA}

Antes de desarrollar el enfoque metodológico, es necesario establecer el significado de los términos que se están usando (dinámica del motor, competitividad, producto turístico, planificación del espacio turístico), de esta manera se pretende ser más 
efectivos (pertinentes) en el desarrollo de la metodología. Existen numerosas acepciones que pueden tomar los términos propuestos, las cuales dependen del área en que se aplique (medicina, ingeniería, gerencia, entre otros). Esconvenientepartirdelos conceptos generales ylosaceptadosenlas experiencias desarrolladas sobreel temade funcionamientodesistemas.

Dinámica del motor: se desarrolla estudiando sus principales componentes. Se puede describir como un sistema rígido con dos discos uniformes concéntricos conectados entre sí (el eje y el imán cilíndrico), que experimentan fuerzas de fricción básicamente en el punto de unión del estator y el rotor (periferia del imán y apoyo del eje). La expresión final, corresponde a la variación de la aceleración angular, una vez calculada la aceleración angular del motor, es posible establecer la velocidad angular que alcanza en función del tiempo (Saldoval, 2010).

Competitividad: las empresas logran ventaja competitiva mediante actos de innovación. Enfocan su innovación en su sentido más amplio, que comprende tanto nuevas tecnologías como nuevos modos de hacer las cosas. Encuentran nueva forma de competir o mejores medios para competir al modo antiguo. La innovación pude manifestarse en el diseño de un nuevo producto, en nuevo proceso de producción, en un nuevo método comercial, en un nuevo modo de llevar a cabo la formación y capacitación del personal. Buena parte de las de las innovaciones son banales y marginales, y dependen más de la acumulación de pequeñas intuiciones y progresos que dan un gran logro tecnológico. A menudo, implican ideas que ni siquiera son nuevas, ideas que estaban por ahí pero que nadie ha llevado a cabo con tesón. Y que siempre implican inversiones en destreza y conocimiento, así como en bienes físicos y en la reputación de la marca (Porter, 2003)

Producto turístico: los productos constituyen una de las cuatro variables del llamado marketing mix y, sin duda, una de las más importantes pues representan el satisfactor de las necesidades de los consumidores lo cual se logra mediante diferentes técnicas y medios. Los productos turísticos son ofertas de diferentes tipos que se preparan para ser brindadas al turista en forma de actividades y servicios, mediante el empleo de diferentes tecnologías y/o instalaciones. Deben ser capaces de motivar visitas a un lugar tanto por un corto tiempo hasta de varios días, para satisfacer un interés o necesidad específica de determinados servicios: recreativos, naturales, culturales, de salud u otros, o una combinación de varios de ellos, y que, además, propicien las mejores experiencias. Los productos turísticos se organizan atendiendo a las características de los segmentos de mercado y en especial, a la motivación que origina el viaje, la cual es la condicionante principal en el diseño de todo producto turístico. Por ello también cuando se popularizan determinadas modalidades turísticas se comienza a hacer referencia a nuevos productos como, por ejemplo, turismo rural, turismo gastronómico entre otros (Salinas, 2009). 
Planificación del espacio turístico: la planificación física es una técnica que pertenece a las categorías fácticas del conocimiento científico. Su finalidad es el ordenamiento de las acciones del hombre sobre el territorio y se ocupa de resolver armónicamente la construcción de todo tipo de cosas, así como de anticipar el efecto de la explotación de los recursos naturales. Existen dos tipos generales de planificación física, la planificación del espacio urbano y la planificación del espacio natural. Además El lenguaje del planeamiento maneja siete tipos distintos de espacio físico (real, potencial, cultural, natural, virgen, artificial y vital). Algunos de éstos corresponden a distintas expresiones materiales del espacio físico (cultural, natural, virgen, artificial), otros son calificaciones conceptuales propias del planeamiento (real y potencial) y uno de ellos pertenece al campo de la ecología (vital). La mejor forma de determinar un espacio turístico es recurrir al método empírico, por cuyo medio se puede observar la distribución territorial de los atractivos turísticos y de la planta, a fin de detectar las agrupaciones y concentraciones que saltan a la vista. De este modo, por medio de un procedimiento sistemático y de la aplicación de las metodologías específicas, se pueden encontrar todos los componentes del espacio turístico que se señalan a continuación, los cuales se han anotado en escala descendente con relación al tamaño de su superficie: zona, área, complejo, centro, unidad, nucleó, conjunto, corredor, corredor de traslado, corredor de estadía (Boullón, 2006).

Para el desarrollo metodológico de la oferta de destinos turísticos, se empleó el enfoque sistémico-mecánico, con base en la propuesta alternativa de funcionamiento del sistema turístico, empleando los siguientes métodos teóricos; método analítico, método lógico y método de la concreción. 


\section{Modelo alternativo de funcionamiento del sistema turístico}

Gráfico 1. Modelo alternativo de funcionamiento del sistema turístico

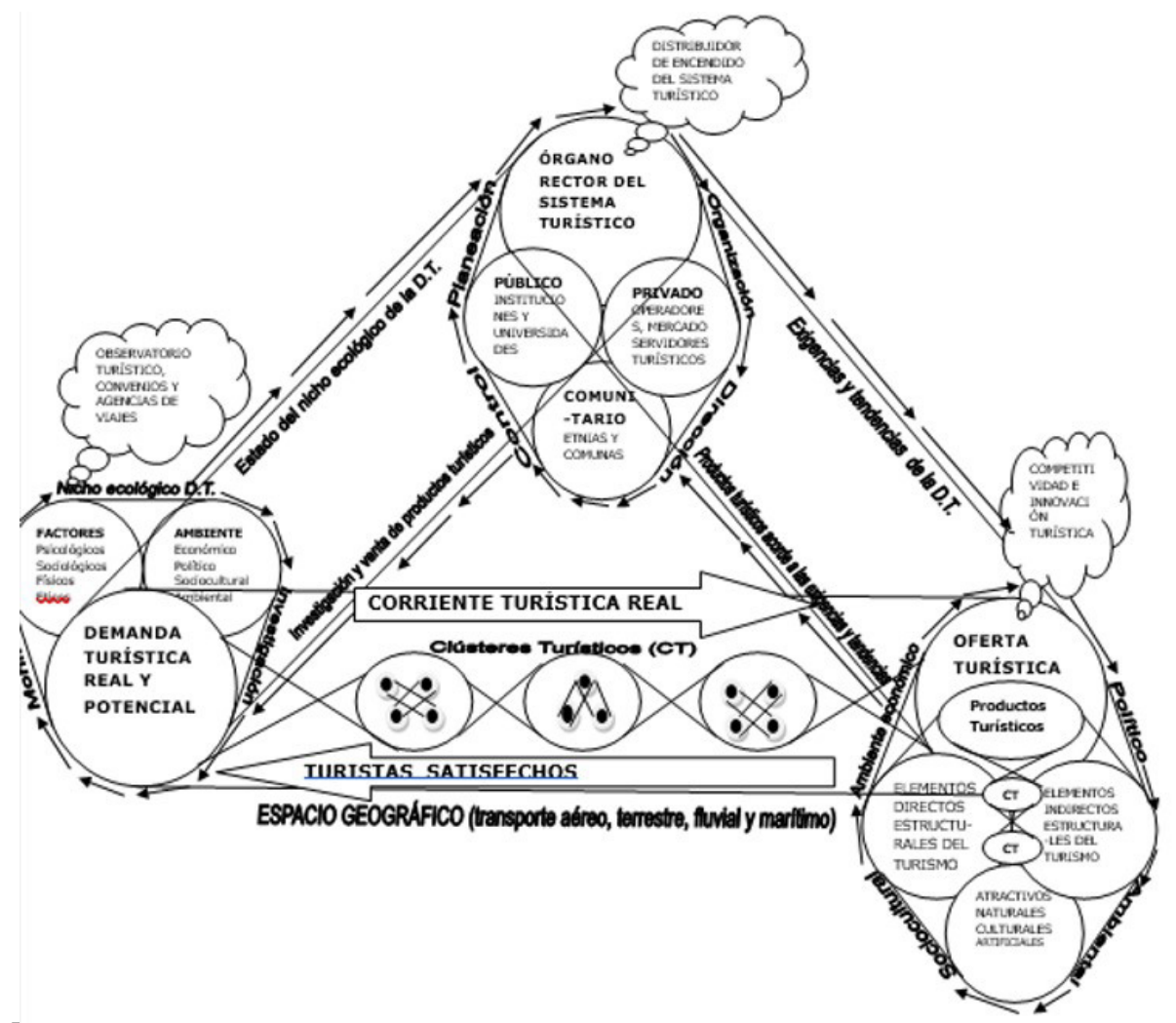

Fuemle: AUariad $(\angle 01 /: 04 /)$

El presente modelo alternativo de funcionamiento del sistema turístico se lo realizó con base en los modelos de Roberto Boullón, Neil Leiper y la OMT, está compuesto de cuatro partes: órgano rector del sistema turístico, demanda real y potencial, espacio geográfico y la oferta del sistema turístico, que funcionando de una forma coordinada, armónica y rutinaria e interrelacionados entre sí, como una estructura real mecánica, que cada una de sus partes dependerá de la otra consecutivamente, obtienen un funcionamiento eficiente, y aprovechan de manera sostenible los beneficios de la cadena de valor del gasto turístico (Abarca, 2017). 
La fortaleza de este modelo alternativo de funcionamiento del sistema turístico radica en el entrelazamiento entre todos sus componentes proporcionando una estructura compacta y que todo su funcionar va a depender del entendimiento del nicho ecológico de la demanda turística, comprendiendo al nicho ecológico como "la posición relacional de una especie o población en un ecosistema o en el espacio concreto que ocupa en el ecosistema. En otras palabras, cuando hablamos de nicho ecológico, nos referimos a todas las actividades que realiza (ocupación), o la función que desempeña cierto individuo dentro de una comunidad" (Carabias \& Meave, 2009). Teniendo presente que de la investigación y monitoreo constante del nicho ecológico de la demanda turística emergerán los gustos, preferencias, necesidades, exigencias y tendencias de las corrientes turísticas del destino, que sarán la luz y guía para el funcionar mecánico de las cuatro partes del sistema turístico, en especial de los servidores y/o empresarios del motor de la oferta turística, quienes tendrán que adaptarse, fortalecerse y moldearse a estas características de su demanda para que mediante la competitividad empresarial, innovación turística y tecnológica puedan satisfacer a plenitud a la demanda turística del sistema.

Cabe resaltar que el presente ensayo va a diseñar y desarrollar metodológicamente la parte de la oferta del sistema turístico expuesto en el gráfico 1, explicando claramente los pasos a seguir para obtener el funcionamiento ideal del motor de la oferta turística. Para mayor detalle se describen a continuación.

\section{RESULTADOS Y DISCUSIÓN}

El presente ensayo nace del interés de efectivizar el funcionamiento de la oferta turística del modelo alternativo de sistema turístico propuesto, para ello a la oferta se la percibe como un gran motor intangible que debe ser diseñado y armado pieza por pieza, narrando el desarrollo metodológico que debe darse en un destino turístico, resaltando que la oferta no puede seguir funcionando con partes y/o piezas separadas que no se conectan entre sí, y que a su vez se preguntan ¿Por qué no se desarrolla el turismo?, a continuación se presenta el diseño del motor y su funcionamiento ideal, recalcando que en primera instancia es imperante conocer a plenitud los gustos, preferencias, necesidades, exigencias y tendencias de la corriente turística del sistema y/o destino turístico a desarrollar, estos insumos deben guiar la inversión (pública-privadacomunitaria), planeación del espacio turístico, jerarquización de los atractivos, diseño

de sistemas de manejo del impacto de los visitantes, y desarrollo de la atractividad del destino. El marketing debe ser el reflejo y proyección de estas características de la demanda (gustos, preferencias, necesidades, exigencias y tendencias de la demanda real 
y potencial), despertando tanto interés en la demanda potencial al igual que una golosina a un niño, satisfaciendo in situ a plenitud las expectativas de la demanda real, ya que esta será el detonante del posicionar del destino en el mercado turístico mundial.

Gráfico 2. Diseño del motor de la oferta del sistema turístico

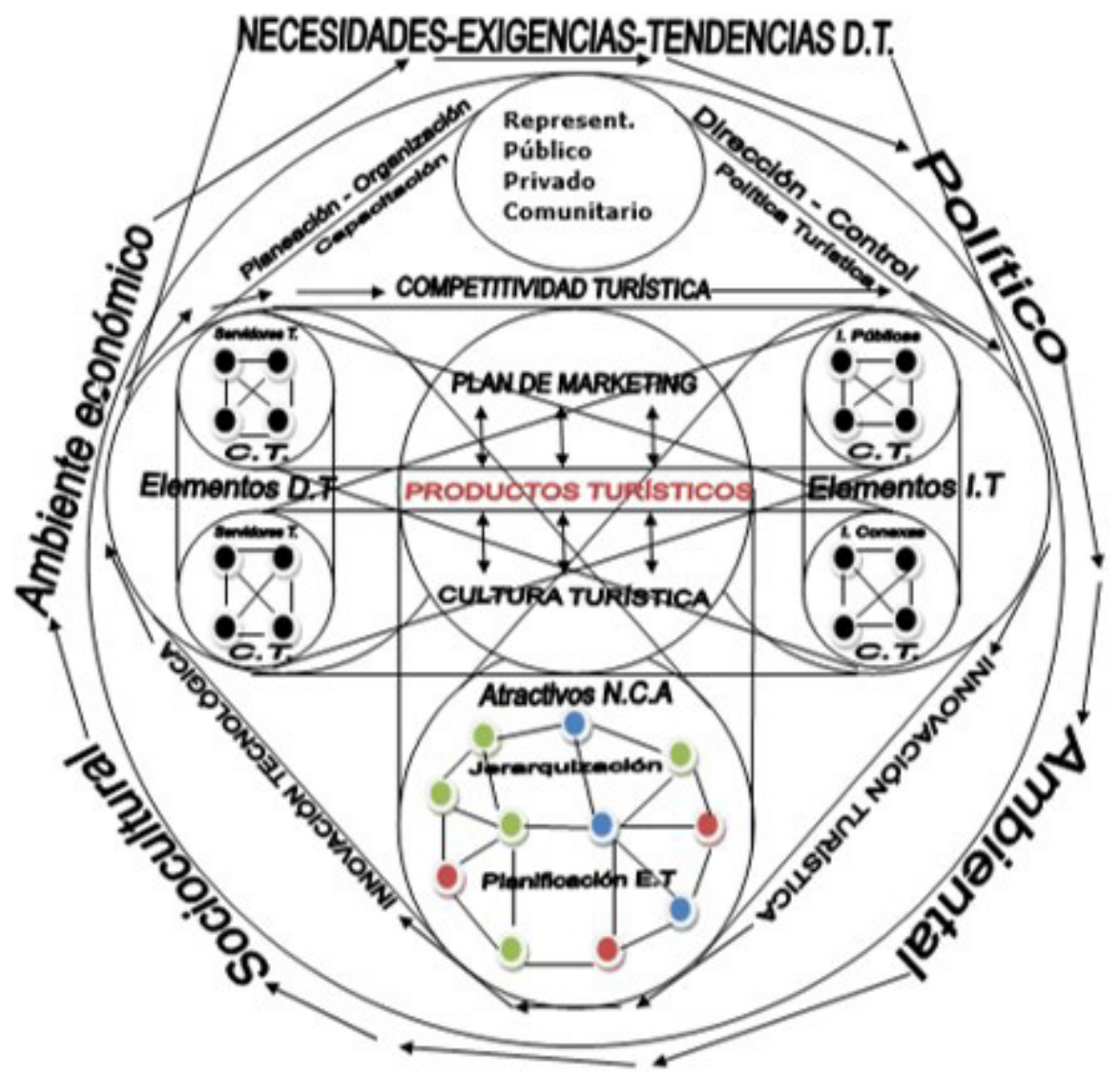

Fuente: Elaboracion propia 


\section{Componentes del motor de la oferta del Sistema Turístico}

La oferta de un destino y/o sistema turístico está conformado por todos los servicios y/o productos turísticos (atractivos + facilidades + accesibilidad) que a través de la innovación, tecnología, competitividad, talento humano, política y economía, se puedan crear y posicionar en el mercado turístico mundial. Estos productos turísticos están integrados por los atractivos naturales, atractivos culturales, atractivos artificiales, elementos directos del turismo y elementos indirectos del sistema turístico.

\section{Atractivos naturales, culturales y artificiales:}

Son el atractivo y motivo de viaje de los turistas; los atractivos naturales están compuestos por toda la belleza comparativa de biodiversidad y geografía de las ecozonas, ecoregiones, biomas o ecosistemas existentes en el sistema turístico en análisis. Los atractivos culturales se conforman de la diversidad de etnias y comunas existentes en la zona. Los atractivos artificiales son los fabricados, construidos y /o elaborados por el hombre existentes en el sistema turístico.

Todos los atractivos naturales, culturales y artificiales deben ser inventariados y jerarquizados de manera objetiva y profesional por el órgano rector del sistema turístico, sean estos; públicos, privados y/o comunitarios. Además esta información debe fluir con toda normalidad, tipo base de datos, con acceso de todos los servidores turísticos, teniendo presente que los atractivos antes mencionados son la plataforma para la creación de posibles productos turísticos.

\section{Elementos estructurales directos del turismo:}

Son todos los servidores y/o empresarios que legalmente constituidos integran el catastro turístico del sistema en análisis, giran en torno a la satisfacción de las necesidades de transporte, hospedaje, alimentación, recreación y bienestar de la corriente turística real, aquí podemos encontrar a establecimientos hoteleros, extrahoteleros, restaurantes, empresas de transporte aéreo-terrestre-fluvial o marítimo, establecimientos de recreación, parques temáticos, naturales, bares,supermercados, complejos deportivos entre otros que se encuentren operando en el sistema turístico. 
El órgano rector del sistema turístico, debe proporcionar a todos los servidores y/o empresarios, información periódica del comportamiento (exigencias y tendencias) de la demanda turística real y potencial, por medio de los representantes públicos, privados, y comunitarios que lo integran, teniendo presente que, esta información debe guiar las funciones de planeación, organización, dirección y control del sistema turístico.

Todos los servidores y/o empresarios turísticos tienen que ser capacitados regularmente, por el órgano rector del sistema turístico propuesto, en temas de atención al cliente, manejo de grupos, innovación turística, relaciones públicas, funciones de la administración de una empresa, manejo de las herramientas del marketing, creación de productos turísticos competitivos, entre otros temas pertinentes a las exigencias y tendencias de las corrientes turísticas reales y potenciales de su sistema.

Los servidores y/o empresarios turísticos deben conformar clústeres que compartan y persigan objetivos y estrategias similares, como se puede apreciar en el gráfico del modelo de funcionamiento del sistema turístico propuesto, conjuntos de puntos conectados por líneas, eso significa que cada punto es un servidor y/o empresario turístico, cada conjunto de puntos es un clúster turístico y las líneas que los unen representan la fluidez de información que tiene que existir entre empresarios y/o clústeres turísticos, esta información debe girar en torno a la experiencia de atención a los turistas de parte de cada uno de ellos, sin guardarse ninguna experiencia con síntomas de celos empresariales, no pueden verse entre ellos como competencia, porque la competencia está en otros sistemas turísticos, más no en este sistema en análisis, mientras más gruesa sea la línea que una a los servidores y/o clúster turísticos mayor será la efectividad y/o rentabilidad del sistema y mientras más delgada sea la línea antes mencionada, menor será la efectividad con la que funcione el sistema turístico, que con el tiempo dejará de funcionar y existirán malas experiencias en los turistas, bajo aprovechamiento sostenible del gasto turístico, no reactivación de la economía, pobreza, cierre de empresas, entre otros.

La innovación tecnológica turística con base a la información del comportamiento de la demanda real-potencial y experiencias de atención a la corriente turística in situ, debe guiar la creación de nuevos productos turísticos, que generen un constante dinamismo (actividades-servicios adaptados a las exigencias y tendencias de la demanda) en los servidores y/o empresarios de la oferta turística, que no permita llegar al declive del sistema en análisis. Además, se debe crear un software que permita la fluidez de la información antes mencionada entre todos los servidores y/o empresarios turísticos, con oficinas en los terminales terrestres, aeropuertos y puertos marítimos, que satisfaga las necesidades de alojamiento, alimentación, recreación entre otros, de los turistas que no hayan adquirido un inclusive tour (todo incluido). El software debe contar 
con un amplio portafolio de servicios, basado en costos, que permitan al turista escoger opciones y automáticamente obtenga el servicio que satisfaga a plenitud sus necesidades, con tan solo pinchar en una opción del software.

\section{Elementos estructurales indirectos del Turismo:}

Son las instituciones públicas encargadas de la construcción de vías de comunicación y trasporte, servicios generales como: agua potable, luz, alcantarillado, salud, educación e industrias conexas, sean estas mixtas, privadas y/o comunitarias que ofrezcan servicios bancarios, tecnológicos, de seguros entre otros, que no necesariamente tengan contacto en primera instancia con el turista, pero que son de suma importancia para el diseño de productos y funcionamiento efectivo del sistema turístico.

Necesariamente en la formación de clústeres y productos turísticos de la oferta, deben constar los elementos indirectos del turismo, de acuerdo a la pertinencia de sus objetivos. Además la oferta turística debe vestirse de un buen ambiente político, económico, y sociocultural, que se vea reflejado en los ambientes que conforman el nicho ecológico de la demanda turística, puestos en valor por los residentes a la hora de tomar la decisión de viajar hacia un destino turístico.

\section{Funcionamiento del motor de la oferta del sistema turístico}

Para obtener un eficiente funcionamiento del motor, hay que cambiar el enfoque de desarrollo de destinos turísticos actual, semejante al cambio de marca del aceite de motor de un vehículo. Los destinos turísticos actualmente tienen un enfoque de desarrollo turístico de ejecución de estrategias, planificación, inversión económica y de talento humano desde la oferta, en otras palabras desde los ojos y criterio de los elementos directos (servidores y/o empresarios turísticos) e indirectos del turismo (instituciones públicas e industrias conexas), motivados por la interpretación subjetiva de los estudios de mercado de la demanda, por ejemplo; analicemos cómo es que son contratados la mayoría de los empleados de las micro empresas turísticas de un destino turístico, son contratados con base en el criterio de los dueños de los negocios y sus políticas, pueden ser estas entrevistas personales o demostración de la experiencia del aspirante, entre otros. Si fuera el caso de un bar la mesera/o va a ser contratado según el criterio de la dueña/o del bar; imagínense lo contario, si en vez de contratarlo según los criterios y políticas del dueño/a, se lo contratara según los criterios y políticas de los clientes del bar, puede ser a través de la unión de un grupo de diez clientes regulares (cinco hombres y cinco mujeres) y estos sean los que lo entrevisten y decidan en consenso contratar o no al mesero/a de acuerdo a sus gustos preferencias, necesidades, exigencias y tendencias. 
En otras palabras los actuales modelos de desarrollo turístico permiten al dueño/a del bar contratar al mesero/a según su criterio y no desde los gustos, preferencias, necesidades, exigencias y tendencias de sus clientes y/o demanda, ya que, en la subjetividad de interpretación de las características antes mencionadas se encuentra el sesgo de los actuales modelos de desarrollo turístico. Con este pequeño ejemplo se explica el enfoque que hay que cambiar en los modelos actuales de desarrollo y funcionamiento del motor de la oferta turística, para no seguir intentando que los turistas o clientes se adapten o moldeen a los criterios y políticas de la oferta, más bien lo ideal sería que la oferta se adapte y moldee a los gustos, preferencias, necesidades, exigencias y tendencias de su demanda turística real y/o potencial.

Es así que desde la jerarquización de atractivos y planificación del espacio turístico de destino, hasta las grandes inversiones económicas (públicas, privadas y comunitarias), estrategias y políticas deben hacerse y ejecutarse con la finalidad de cerrar la brecha existente entre lo que la demanda necesita y solicita, versus los productos y servicios turísticos que la oferta ofrece actualmente, de tal forma que permita a las corrientes turísticas disfrutar a plenitud del destino que ellos desean visitar en base a sus exigencias, necesidades y tendencias y no el destino que los ofertantes turísticos quieren que ellos visiten.

El nuevo enfoque de funcionamiento del motor de la oferta turística debe ser el cumplir a plenitud los gustos, preferencias, necesidades, exigencias y tendencias; insumos resultantes del estudio del nicho ecológico de la demanda turística real y potencial, con un funcionar mecánico que permita a los tres rotores del motor del sistema un funcionamiento efectivo y rentable. Cabe resaltar que no es aconsejable desarrollar un destino turístico sin contar con un órgano rector que lo administre (planeación, organización, dirección y control), teniendo presente que este órgano rector del sistema es el responsable de la investigación y monitoreo continuo del nicho ecológico de la demanda turística, que a su vez transmite continuamente sus gustos, preferencias, necesidades, exigencias y tendencias a los integrantes de los rotores del motor de la oferta turística permitiéndoles adaptarse a estos insumos y ofrecer exactamente lo que la demanda necesita y exige.

La competitividad, innovación turística y tecnológica deben ser en el motor de la oferta, las bandas de distribución que hagan girar los tres rotores (elementos directos, indirectos y atractivos turísticos naturales, culturales y artificiales) del motor para obtener productos turísticos competitivos e innovadores acordes a los gustos, preferencias, necesidades, exigencias y tendencias de su demanda. 
Los clústeres turísticos deben estar bien atornillados por medio de buenas estrategias conjuntas de comunicación, desarrollo empresarial y mejoramiento de sus servicios, a su vez se recomienda que estos clústeres se encuentren integrados por empresarios y/o emprendimientos turísticos (privados y comunitarios), instituciones públicas e industrias conexas. Además, el combustible y/o bandas que hagan girar los clústeres deben ser los gustos, preferencias, necesidades, exigencias y tendencias de sus demandas turísticas.

Los empresarios y/o emprendimientos turísticos, instituciones públicas e industrias conexas que conformen o no conformen los clústeres de la oferta deben estar todos interconectados entre sí, por medio de un flujo continuo de ida y vuelta de información y comunicación sobre sus experiencias obtenidas en el trabajo de satisfacer a plenitud los gustos, preferencias, necesidades, exigencias y tendencias de sus demandas, sin verse como competencia entre ellos con el objetivo de fortalecerse y ofertar los productos y servicios turísticos exactamente como la demanda turística lo necesita y exige..

El plan de marketing debe ser el contraste entre: el resultado y reflejo de los gustos, preferencias, necesidades, exigencias y tendencias del estudio constante del estado del nicho ecológico de la demanda turística real y potencial; y el resultado de la interpretación de las potencialidades de la atractividad del destino de parte de los planificadores del desarrollo turístico. En otras palabras hay que proporcionar a través de las herramientasdel marketing a la demanda turística real y/o potencial lo que ellos quieren escuchar, ver y tener sobre el destino turístico, no lo que la oferta por medio de las interpretaciones multidisciplinares de los planificadores del desarrollo turístico quieran a través de las herramientas del marketing hacerles escuchar, ver y tener sobre el destino turístico, primordial para asegurar el flujo constante de las corrientes turísticas.

La efectividad del funcionamiento del motor de la oferta turística, va a depender del poder de atractividad de los productos turísticos que oferten, estos a su vez serán sostenibles en el tiempo solo si se logra mitigar los impactos (económicos, socioculturales y ambientales) negativos de las corrientes turísticas, por medio del diseño y ejecución de sistemas de manejo del impacto de las corrientes turísticas, que les permita tomar acciones correctivas inmediatas a los administradores de los atractivos (naturales y culturales) en el momento en que ellos detecten que el impacto sobrepasa el límite permisible determinado en el sistema de manejo.

La cultura turística debe ser la acumulación histórica de experiencias del trabajo arduo de satisfacer los gustos, preferencias, necesidades, exigencias y tendencias de sus corrientes turísticas, en continuo contraste con el folkore del nicho ecológico de su demanda turística real y potencial. 
Las políticas turísticas internas del sistema serán emitidas por su órgano rector y deben ser aditivos que mejoren y aceleren el funcionamiento de los rotores del motor de la oferta turística, estas políticas deben diseñarse para fortalecer el trabajo de satisfacer los gustos, preferencias, necesidades, exigencias y tendencias de su demanda turística real y potencial por los servidores $\mathrm{y} / \mathrm{o}$ empresarios turísticos.

La capacitación continua de los servidores y/o empresarios turísticos de parte del órgano rector del sistema turístico, debe ser otro aditivo que fortalezca, mejore y acelere el funcionamiento de los rotores del motor de la oferta, en temas pertinentes y necesarios a la satisfacción de los gustos, preferencias, necesidades, exigencias y tendencias de su demanda turística real y potencial.

Los productos y/o servicios turísticos del sistema (atractivo + facilidades + accebilidad) serán el resultado competitivo e innovador del funcionamiento coordinado y encadenado de los tres rotores del motor de la oferta turística, reflejo del trabajo de la búsqueda continua de satisfacer a plenitud los gustos, preferencias, necesidades, exigencias y tendencias de su demanda turística real y potencial. Estos productos y/o servicios deben ser diseñados y vendidos por el órgano rector del sistema turístico.

Diseñados con un enfoque de desarrollo endógeno con base en los atractivos turísticos (naturales, culturales y artificiales), servidores y/o empresarios turísticos, instituciones (públicas, privadas, comunitarias) e industrias conexas de la oferta turística del sistema.

Los ambientes (económico, político, sociocultural y ambiental) externos al sistema turístico en análisis, serán los encargados de regular la temperatura propicia (microclimas y micro ambientes) para el funcionamiento eficaz y rentable de los rotores del motor de la oferta turística.

\section{Desarrollo metodológico de la oferta del sistema turístico}

La oferta turística debe ser flexible, moldeable y adaptable a los gustos, preferencias, necesidades, exigencias y tendencias de su demanda real y potencial. Estos deben convertirse en la base estructural del diseño, creación e innovación de productos y/o servicios turísticos del sistema y responder la pregunta ¿Qué es atractivo para la demanda turística? pregunta fundamental que deben hacerse los planificadores del desarrollo de un destino turístico. Hay que tener presente que no se puede invertir o ejecutar estrategias de desarrollo turístico desde la oferta. 
La jerarquización de atractivos y planificación del espacio turístico del destino, deben realizarse desde los ojos (gustos, preferencias, necesidades, exigencias y tendencias) de sus corrientes turísticas y no desde el criterio profesional de los planificadores del desarrollo turístico, porque pueden estos últimos caer en la subjetividad profesional y en la limitación relativa a sus gustos, preferencias, necesidades, exigencias y tendencias y no al de la corriente del sistema turístico en desarrollo, explicando que la subjetividad es "el contrapunto entre contenidos teóricos permanentes y la transitoriedad de los sujetos" (Leff, 2010). Además pueden terminar aplicando modelos de desarrollo turísticos de avanzada no pertinentes a las necesidades, gustos, preferencias, exigencias y tendencias de la demanda del sistema turístico a desarrollar.

La jerarquización y planificación del espacio turístico de destino,debe realizarse con base en la contrastación de estudios piloto de las corrientes turísticas reales in situ, visitando los atractivos, y la interpretación eficiente de sus gustos, preferencias, necesidades, exigencias y tendencias de parte de los planificadores del desarrollo turístico. La sostenibilidad de los atractivos naturales y culturales de un destino turístico, será posible diseñando, ejecutando y monitoreando sistemas conjuntos de manejo del impacto de los visitantes y/o corrientes turísticas.

A continuación se describen los pasos a seguir para operativizar eficientemente el funcionamiento del motor de la oferta turística desde un enfoque sistémico-mecánico de funcionamiento endógeno con base en los gustos, preferencias, necesidades, exigencias y tendencias de la demanda real y potencial del sistema turístico.

- El primer paso nace de la pregunta ¿Cuáles son las característica del nicho ecológico de la demanda turística?, en este estudio y análisis de identificación de las características de su demanda (gustos, preferencias, necesidades, exigencias, tendencias y procedencia), debe establecer claramente el nicho de mercado al cual pretende desarrollar. Lo más importante del primer paso radica en no conformarse solo con un estudio de mercado de la corriente turística real en las grandes ciudades tipo centros de distribución turística o en los productos turísticos de destino, si no en contrastar esta información obtenida; versus el resultado del estudio del estado del nicho ecológico de la demanda real y potencial en sus los lugares de residencia.

- $\quad$ El segundo paso es establecer mediante análisis conjunto y multidisciplinario, la brecha existente entre los gustos, preferencias, necesidades, exigencias y tendencias de la demanda turística real y potencial que se ha obtenido en el primer paso; versus la infraestructura, componentes, atractivos jerarquizados, espacio turístico planificado, tipo de servicio e integrantes del motor de la oferta 
que tiene actualmente en el destino turístico. Al caracterizar esta brecha se obtendrán los insumos necesarios para diseñar, crear y adaptar el motor de la oferta turística a los gustos, preferencias, necesidades, exigencias y tendencias de su demanda.

- $\quad$ El tercer paso será diseñar, ejecutar y monitorear el plan estratégico de desarrollo turístico mancomunado con base en los insumos obtenidos en el paso 2, que tendrá como objetivo general, realizar inversiones (económico y talento humano), diseñar políticas y estrategias mancomunadas que les permita a los elementos directos, indirectos, y atractivos turísticos (naturales, culturales y artificiales) adaptarse dinámicamente a los gustos, preferencias, necesidades, exigencias y tendencias de su demanda turística real y potencial, cubriendo la brecha antes mencionada de manera óptima, permitiendo a los tres rotores del motor de la oferta turística funcionar con mayor eficacia y rentabilidad.

- El paso final del proceso de desarrollo metodológico de un destino turístico, es la construcción estratégica y planificada del día a día de la cultura turística del destino, con base en los gustos, preferencias, necesidades, exigencias y tendencias de su demanda turística real y potencial, tipo reflejo del accionar y proceder del imaginario colectivo del nicho ecológico de su demanda Turística.

\section{CONCLUSIONES}

El motor de la oferta del sistema turístico está compuesto por tres rotores (elementos directos e indirectos del turismo, y los atractivos naturales, culturales y artificiales del sistema turístico) que giran por medio del movimiento de la banda de distribución (competitividad, innovación turística y tecnológica) generando productos turísticos competitivos e innovadores.

La política turística interna y la capacitación continua, aplicada e impartida a los servidores y/o empresarios turísticos de la oferta del sistema, son los aditivos que permitirán que los rotores del motor de la oferta giren a mayor velocidad y efectividad en su trabajo de satisfacer a plenitud los gustos, preferencias, necesidades, exigencias y tendencias de la demanda turística real y potencial.

Los gustos, preferencias, necesidades, exigencias y tendencias de la demanda real y potencial del sistema turístico en análisis, serán la luz y guía del nuevo enfoque de desarrollo de destinos turísticos. Enfoque que dará sostenibilidad a todo el proceso de funcionamiento de los rotores del motor de la oferta del sistema turístico, siendo la rentabilidad de los servidores y/o empresarios turísticos 
relativos a la velocidad con la que giren los tres rotores del motor de la oferta del sistema turístico.

La sostenibilidad de la atractividad del destino y/o sistema turístico será el resultado del diseño, ejecución y monitoreo de uno o más sistemas de manejo del impacto de visitantes in situ (atractivos naturales y culturales), que les permita a los administradores de los atractivos mitigar los impactos económicos, socioculturales y ambientales negativos producidos por las corrientes turísticas del sistema.

\section{BIBLIOGRAFÍA}

Abarca, M. A. (2017). Propuesta de un modelo alternativo de funcionamiento del sistema turístico. European Scientific Journal , 355.

Boullón, R. C. (2006). Planificación del Espacio Turístico. México: Trillas.

Carabias, J., \& Meave, V. C.-S. (2009). Ecología y Medio Ambiente en el siglo XXI. Mexico: Pearson Edicación.

Leff, E. E. (2010). Sujeto, subjetividad, identidad y sustentabilidad. Revista de la Universidad Bolivariana, 12.

OMT. (2016). Panorama OMT del turismo internacional. España: OMT.

Porter, M. E. (2003). Ser Competitivo Nuevas aportaciones y conclusiones. BarcelonaEspaña: Deusto.

Saldoval, K. P. (2010). Modelo experimental de un motor unipolar. Fac. Ing. Univ. Antioquia, 173.

Salinas, C. E. (2009). Los productos turísticos, pilares de lacomercialización. Dos ejemplos del centro histórico de la Habana, Cuba. Estudios y perspectivas en turismo, 1851- 1732.

UNWTO. (2016). UNWTO Tourism Highlights 2015. Publicaciones OMT. 